\title{
International Student Academic Support: Academic Support given to Chinese International Students from Teachers
}

\author{
JesAlana Stewart
}

\begin{abstract}
With the large flux of international students attending American universities in order to achieve a higher level of education, it is imperative that these institutions provide sufficient resources to enable them to succeed. The vast majority of these students have had no experience with the western academic system, and they need an academic cultural ambassador to guide them in this setting. The foremost resource in helping these non-native students to navigate academia is the teacher. This study takes a qualitative approach of four case studies of freshman composition instructors of international students in order to develop the perspective of a first line of defense. This research finds many commonalities among the perspectives of these teachers, particularly in how empathic these instructors are towards their non-native students, and it reveals many forms of accommodations that they make in order to help their students succeed. It discovers that from the perspective of these teachers, this particular group of students will only use the resources that they are encouraged to utilize by each individual instructor (even when there are other known services available to them). Furthermore this study calls for more research into the available resources that international students use, more training for teachers who are going to instruct this very diverse population, and it advocates for the development of further resources for the future.
\end{abstract}

Keywords: international students, English composition, western rhetoric

\section{Introduction}

With the rise of international students coming to the United States for higher educational purposes, and a majority of these students being Chinese, there is an increased need for an understanding of how to accommodate the academic requirements of these students. In order to truly facilitate the educational growth of this specific group, it is essential to first recognize the various difficulties that they encounter, and to assist students in coping with these difficulties. Those who are aware of these struggles are essentially the first line of defense for international students. They know these students as individuals and realize the different challenges that they face as non-native speaking (NNS) students. Finally they 
combat stereotypes and guide these disenfranchised students through a new and complicated system of education. They are the teachers.

\section{Literature Review}

When looking at the academic support given to students directly from teachers it is important that both students and instructors have a heightened awareness of and respect for the rhetorical differences of the two cultures. For example, the conventions of writing in regards to plagiarism, supporting evidence, and the logical progression of thought, are all vastly different depending on the culture. Thus it is important to understand these differences, which is best accomplished through an orientation that does not disregard either culture as a deficit, but rather allows for the positive transfer of strengthened rhetorical devices from L1 Chinese, in combination with an understanding of the appropriate writing conventions of native speakers (NSs) in L2 English. This, therefore, leads to a stringent dichotomy in the teaching of English composition. Either the instructor must teach students a Standard English while avoiding cultural disenfranchisement, which is most successfully accomplished through an intercultural rhetoric (IR) perspective (Connor, 2011), or they must teach them how to navigate translingual practices (Canagarajah, 2013), where students may incorporate all language practices that they are aware of, to develop a new and interesting type of personal rhetoric.

It is important when dealing with the dichotomy between Intercultural Rhetoric and Translingual Practices that both theoretical orientations work together to keep each side in check. It is because the weakness of one theory is the strength for the other that these ideas could work together in practice to fulfill the needs of both students and audience, without disenfranchising either one. For example, the foreseen difficulty of Translingual Practice is the possibility for the incomprehension of a native readership, which Intercultural Rhetoric attends to, while the criticism of Intercultural Rhetoric is the disenfranchisement of the student, which Translingual practice appeases. So rather than discount both as inadequate theories, it stands to reason that the interplay between the two theories, and the exchange of various cultures and rhetorical traditions, could be a beneficial combination and the orientation needed to create validity and acceptance of international students' writing.

In other words, when the writing of an international student is found to be near incomprehensible to a native speaking readership of English, perhaps this learner would benefit from the overt instruction of IR. If, however, this form of writing exhibits interesting and culturally enriching rhetorical moves and is simultaneously understood by a sympathetic native audience, then a Translingual approach would be more suited. These examples, of course, are the two extremes and any combination of the two theoretical frameworks would be of great benefit to NNS English compositions.

Thus, there has been a call for research in how to teach NNS's English composition in a way that does not marginalize or patronize them. Mina Shaughnessy has advocated research since the 1970's that not only looks into 
pedagogies that work for both the students and the teachers who "grapple with words and methodologies they don't understand, experiencing as they do all the frustrations and embarrassments of the person who must say something important in a strange language" (Shaughnessy, 1973); but that also highlights the need for formal training of teachers who instruct writing to various disenfranchised students (Shaughnessy, 1998). She highlighted the growing phenomenon of diversity in the classroom, and how many of these students "shared the experience of having had their language differences ignored or treated as a disadvantage, (and) of having had the fun and pride of language drained out of their school lives" (Shaughnessy, 1998). Finally, she discussed the tendency of teachers to have "fatalistic views about many of their students difficulties" (Shaughnessy, 1977) because there is a lack of scholarship on the generalization of rhetorical moves and differences, which may help to instruct such students. The need to address all of these issues still exists.

Scholars in the United States such as Thonus $(1993 ; 1999 ; 2001 ; 2002 ; 2003$; 2004), Severino (2004), and Williams (2002) have attempted to address such issues, particularly in relation to help given to students in learning and tutorial centers. Even more authors still, have attended to the question of how to instruct international students with articles written as guides to tutors and teachers (Nan, 2012; Williams, 2002). Thonus (1993) even advises tutors to use Contrastive Rhetoric (mentioned above, as its newer form IR) as a means to raise consciousness in students, and to focus on the student's ability as a reader. These authors give a list of do's and don'ts as a checklist in how to deal with NNSs, and these suggestions are far more helpful than simply instructing a NNS as one would a NS. However, these writers do not actually provide any solid theory or practices that are guaranteed to work for NNSs, and many of these suggestions go against the writing center methodology, or mythology according to Thonus (2001).

This situation further complicates the question of where NNS typically go for help, and whether they prefer tutorials from English Composition Instructors or from the Writing Center Tutorials. Do these students simply go to the form of academic support that they know about, or that is recommended to them? Do they seek out help, and for what reasons? If these students try to get help from unreceptive instructors, will they still be willing to go to tutorial services, or vice versa? Many of these questions go unanswered in the literature.

In order to appropriately answer these questions and to address the needs of NNSs, Thonus (2003) suggests that "by focusing learners' attention on how to write rather than what to write for a particular assignment, by emphasizing a balance between correct grammar usage and sound rhetorical style, and by offering learners explicit direction," instructors have the ability to advance the English writing of NNSs. These suggestions, along with the right attitude towards international students may lead towards positive advancements in teaching of these disenfranchised students, and they all begin with the instructor.

Many authors assert that knowing specific cultural information, particularly about the Chinese rhetorical tendencies and cultural practices, is essential for teachers to be able to assist these learners in a more meaningful way (Connor, 2011; 
Nan, 2012; Severino, 2004; Thonus, 2003; Williams, 2002). In knowing more about the culture and its various rhetorical strategies, teachers are better prepared to attend to these differences. They are more capable of recognizing the rhetorical patterns and highlighting the differences in cultural writing styles, in order to give more effective suggestions (such as those given by Thonus) on how to navigate these distinctions for the L2 writer in a culturally sensitive way.

This entails the differences between the cultures that merge within the classroom. Chinese culture, for example, is often times viewed as a polite culture in contrast to the more abrasive American persona. Since this is the overarching culture of international students at American universities currently, it is essential for researchers to explore the possible forms of dominance between the two cultures. One such example of Chinese polite culture within a tutorial is when "Student $\mathrm{K}$ interpreted (the tutor interrupting) as signaling his interest, consistent with her NNS positive politeness culture, which views face-threatening acts by role superiors more positively than in Western cultures" (Thonus, 2002). Although the instructor interpreted his own behavior as abrasive and forceful, the student rather interpreted his actions as helpful and normal.

Finally, it is also important for teachers to know the difficulties that international students face, because these students are constantly learning new intricacies to a language in which they are expected to write at a higher academic level, which may lead to various misunderstanding. For example, whereas tutorials with NS are dominated by niceties and tactful polite speech, for many "NNSs, this politeness strategy can be a barrier to comprehension" (Thonus, 2004) and actually impedes understanding. In fact Thonus, premeditated this finding with her 2003 research, suggesting that NNS of English actually prefer overt instruction rather than polite suggestions, because this means of educating in a more blatant form is more conducive to their understanding of the new rhetorical strategies in English. Additionally, this form of direct instruction from teachers is more beneficial than harmful to these students. However this places the teacher in a particularly difficult position where they must choose between the dichotomy of being polite while having students misunderstand, or of being direct and having students understand with the possibility of being offended (Thonus, 2004).

\section{Theoretical Framework}

It is evident that a call has been made for better practices in the teaching of English composition to international students in a more effective and responsible manner. However, very little research has looked into the beliefs and expectations of current instructors of this population. Therefore, in order to better understand what perceptions current instructors have of international students and the challenges they believe are prevalent, this research took an ethnographic perspective to collect data and used grounded theory to analyze it. Through this methodology, and in conjunction with the researchers beliefs, this study found three theoretical perspectives working throughout the teacher's perceptions. 
Firstly, a Vygotskian method was found to be useful in the instruction of all students, especially international students. Nakamaru (2010) states that having a Vygotskian orientation can help teachers and tutors enable their students to improve their writing through "scaffolding in expressing what they want to say in the first place, e.g., by providing appropriate vocabulary or modeling the use of idiomatic lexical chunks and sentence patterns." This is echoed to a great extent by Jessica Williams' (2002) study:

The zone of proximal development emerges collaboratively and individually and is subject to constant change. Some learners may be almost ready for self-regulated activity, requiring only the most implicit guidance. Other learners may need far more-and more explicitassistance and continued reliance on an expert for scaffolding of new knowledge. Scaffolding is the support provided by the expert that allows the learner to perform the new task. (p. 85)

Thus, the use of the Vygotskian zone of proximal development (ZPD) and scaffolding provides teachers with the ability to motivate students through knowledge that they already have in order to obtain new information that they may not have been able to achieve on their own. Through this orientation and with the various suggestions that these writers have provided, perhaps teachers in using these techniques will help NNS students to improve in their academic writing abilities. Therefore this study uses a Vygotskian lens to analyze and interpret data gathered from teachers in regards to how they instruct international students. This study particularly focuses on the Vygotskian approach in relation to the means of accommodation that teachers provide students in order to help them achieve a higher level of academic writing.

In conjunction with Vygotsky and his ideas of the ZPD and scaffolding, this research uses the work of Connor (2011). Connor also contributes to the ongoing discussion of accommodation and she further addresses how stereotypes are present in the writing classroom. She therefore uses intercultural rhetoric as a means of appropriately constructing written language depending on the various contexts merging in a writing classroom designed for international students. She explains that in "intercultural rhetoric: (1) texts need to be seen in their full contexts, including their visual rhetoric; (2) small and large cultures interact in complex ways; and (3) interaction in intercultural communication requires accommodation and negotiation, which also requires cultural sensitivity and effective communication strategies" (Connor, 2011). Therefore, this research uses Connor's work as a means for understanding the various contexts that these teachers face, the accommodations that teachers make, and the stereotypes that both emerge in the data and that teachers combat.

Finally, an influential theoretical framework that this research draws from is the work of Pierre Bourdieu (1991). This work deals with the idea of "habitus" and its socially constructed nature, in relation to the linguistic differences of language. These concepts help to analyze coinciding data provided by teachers in regards to their empathy towards students, particularly when the teachers themselves had experienced a shift in their own linguistic habitus. Bourdieu (1991) states, habitus "involves both the linguistic capacity to generate an infinite number of grammatically correct discourses, and the social capacity to use this competence 
adequately in a determinate situation." (p. 37) This concept highlights the difficulty of infinite possibilities when writing in a foreign language, and the necessity for social competence. This need falls on the teachers of international students, particularly in writing, to adequately instruct the context of this new habitus.

These theoretical frameworks, although seemingly very different, function together harmoniously to help analyze emergent data surrounding the accommodations, stereotypes, and empathy that teachers experience with their international students in merging multicultural contexts. The teachers acknowledgement of the various habitus at play in an intercultural writing classroom brings forth an empathy for the difficult context of students, which leads to accommodation in instruction through means of scaffolding, and a struggle against stereotypes that come from the friction of distinct habitus and intercultural rhetorical differences at play in such a context. Thus it is evident that this study draws from each theoretical framework to unearth the cyclical situation and concerns of teaching international students to write in English in a western academic setting. This literature, although vast, does present a few gaps. Therefore, this research will address the following questions:

1. How do teachers understand the positioning of their students as internationals studying abroad and what actions do they take to help this population?

2. In what ways do teachers of this international student population adapt their instruction for their students?

3. According to teachers, where do international students go to for help in their writing of English?

4. Finally, what perceptions do teachers have of both their international students and their job instructing them?

\section{Methodology}

Over the course of a year, a qualitative classroom ethnography was conducted in the form of four case studies. The participants were instructors of a freshman composition course for international students, both the spring and the fall of 2014 . In order to properly triangulate all data gathered, multiple forms were collected. These participants were willing to be both observed and interviewed, while also open to providing course artifacts such as class rosters, syllabi, assignments, presentations, and lesson plans. Therefore each instructor was observed multiple times both in the classroom and in office hours while field notes were being gathered, and they were audio recorded during semi-structured interviews. Due to the semi-structured nature of the interviews, questions were developed in advance (see appendix A), however, additional questions and prompts were asked to clarify. Finally, all interviews went through a rigorous process of member checks where participants approved transcripts and field notes and provided additional information in personal communications. 


\section{Participants}

Four instructors of a freshman composition course geared toward international students volunteered for this research. Two of the instructors were female and two were male, they were chosen based on their veteran status of teaching English composition and diverse backgrounds. A description of each instructor and their teaching mentality follows:

$\mathrm{J}$ is a female instructor of this English composition course with a background in TESOL and a focus on identity discourse. She has several years of teaching experience, particularly with international students, and at multiple large midwestern universities. Her enthusiasm for her work and the empathetic approach to the students makes her both highly accessible to and valued by her students. She is very receptive to all students and has a motherly and accepting demeanor towards each of them as individuals.

$\mathrm{L}$ is also a female instructor with a background in veteran discourse. She too has had many years of experience in teaching English composition, however, her primary experience has been in teaching domestic students. She is the kind of instructor that will highlight a student's good work in order to praise all students on their attempts of a similar construct. She is incredibly attentive toward her students, and adept at anticipating their questions. She is a highly knowledgeable instructor with great concern for the academic development of her students.

$\mathrm{M}$ is a male instructor with a background in medieval literature. He has an enthusiastic personality, which creates an atmosphere of trust in the classroom and makes him easily approachable. He teaches in a very student centered way, and hopes to bring fun to the classroom through various teaching techniques that he has developed over the years.

Finally, $\mathrm{T}$ is a male instructor from Second Language Studies who identifies as a linguist. He takes a more structured approach to instructing the course that is teacher centered. He is highly knowledgeable in the differences of rhetorical devices from L1 Chinese to L2 English, and excels at explaining and conveying these differences to his students. He hopes by breaking down these writing constructs effectively to his students that they may in turn be more successful not only in his class but also in school in general.

\section{Environment}

Despite the fact that every instructor teaches in a different classroom on a large midwestern university, each location maintains a degree of uniformity from one place to another. According to fieldnotes, all the classrooms are rectangular in shape, contain at the bare minimum one chalkboard, and one computer with a projector and screen, and has some degree of windows located within the room. Each classroom contains anywhere from 16-42 desks with attached chairs for the students and some kind of table or podium for the teacher. The classroom that instructor $M$ has contains a large, rather distracting table, which is shoved to the far side of the room underneath the windows. 
In addition to the classroom observations, teachers permitted the researcher to sit in on office hours. All four of the teachers had their office hours directly after class. J and M stayed in the same classroom, if there were no classes scheduled to meet in the same room the following hour. $\mathrm{L}$ and $\mathrm{T}$ chose to have office hours at a different location. Instructor $\mathrm{L}$ had office hours in an office with comparable amenities, which was simply smaller and still in the same building as her class. T also relocated his office hours to a study area/dining area, which again was in the same building as his class. It was understood that the coordinator of this course asked teachers to have office hours in an appropriate public space that would make students feel more comfortable, and that enabled the safety of all parties (document provided by participant).

\section{Outcomes}

To answer research question one, the most salient threads of discussion that ran throughout the interviews with the teachers, revolved around their inherent desire to help their students. M explained his perspective of what his students are going through by saying in an interview, "They are trying to navigate the academic world as an exile. They are fundamentally outside of the academic world, yet they have to work in it" (transcript 3A, p. 8 / audio 27: 41). His concern for his students and the difficulties that they face were the same concerns expressed by all of the teachers, and these concerns led to recurring topics in each of the interviews, such as: empathy, accommodation for the type of instruction their students both want and need, and where to send their students for additional help. There were also discussions of various stereotypes they either fight against or have heard from others, along with a call for help in not only eliminating these stereotypes but in assisting international students in general. These themes resonate directly with the research questions of this study.

These four instructors understand the difficulties that international students face from first hand experiences in their classrooms, which among the many commonalities in the interviews became apparent. Therefore, in response to research question number one, many forms of empathy were noted in interviews, classroom observations, office hours, and personal communications. This empathy emerged from the knowledge of various linguistic habitus being used and formed by students in the writing classroom and is viewed as one of the greatest tools teachers use in order to help their students in the course. According to McAllister and Irvine (2002), "Empathy involves cognitive, affective, and behavioral components that teachers believed were manifested in their practice." One instructor in particular, J, explained in an interview that her own difficulties in learning to communicate in another language helped her to develop this sense of empathy towards her students and gave her personal experience with which to draw from as a means of identifying more with international students. She stated, "I just try to give them pep talks like that...because it's frustrating. I know, and I tell them, too, about my experiences writing in French, and my frustration of not saying things the right way" (transcript 1A, p. 7 / audio 24:59). This expression of divergent habitus between L1 and L2 linguistic codes demonstrated that $\mathrm{J}$ had to overcome similar struggles to those of 
her students, which in turn constructed a deep sense of empathy for her current students.

The other instructors exhibited empathy, as well. L showed immense empathy, not only in her interview and classroom, but also in her office hours. After one particular office hour session with an overly concerned student, L clarified, "we do typically get to some life issue - my goal is to say 'it is not you it's everybody and it's just college'" (fieldnotes-04/28/2014). The male instructors too showed great empathy. M demonstrated this empathy in the way that he encourages students with their topics of interest, which he both demonstrated in class and mentioned in one of the interviews. He stated, "I have adopted a Dead Poet Society mentality of support at all costs... So I find that if I can give any encouragement at all about a topic that usually suffices" (transcript 3A, p. 13 / audio 46:53).

This empathy goes further than simply comforting students through possible stages of culture shock, but also acknowledging that students may need help beyond what they are communicating they need. For example, each of the four teachers agreed that students most often express that they need help with sentence-level errors and grammar, however it is apparent that these students are in need of help in the global rhetorical concerns of writing in western academic speech, which is also a concept from Connor's Intercultural Rhetoric. T explained in an interview:

"I think a lot of them have expressed that they feel that they're not good at writing in English and have trouble with grammatical issues... a lot of them really are thinking in Chinese, and then writing in English. More than that, however, I think one of the biggest things is writing in a western style. In other words, really putting a lot of emphasis on having a coherent main idea, and really supporting that through evidence" (transcript 4A, p. 1 / audio 2:23).

Beyond understanding what the students overtly ask for help with and indirectly need assistance in, there was an overwhelming commonality of accommodation from the instructors for their students. Therefore, answering research question number 2, each instructor discussed the adaptations that they made to their instruction to help these students. M said in an interview, "I find that the more jargon I throw at the students the less they understand" (transcript $3 \mathrm{~A}, \mathrm{p}$. 2 / audio 5:05). J also accommodates her speech, in an interview she explained, "I annunciate things and I talk kind of slower...like...this, sometimes" (transcript 1A, p. 6 / audio 21:19). By adjusting their speech these instructors use terms to scaffold information so that it becomes more accessible to their students. In addition to their speech, many of the teachers incorporate various forms of technology to supplement their instruction and to give students a visual representation of things happening in the course. Again, by using familiar technologies, these instructors use the ZPD to make course objectives more accessible to students. For example, T helped his students more through emails (document); M through texts (interview); J through PowerPoint's, Google calendar, and visuals (interview); and L through PowerPoint's and online course tools such as a class wiki for peer reviews (documents). Beyond technology, many of the instructors insisted that reading was the best way to improve their students writing. J stated, "I tell them a lot... that I learned to be a good writer because of reading" (transcript 1A, p. 6 / audio 22:55). 
The four participants also helped students by accommodating various schedules including offering more of their own time. For example, the three teachers (J, L, M) who advocated office hours and encouraged students to meet with them were consequently the instructors that saw more of their students in person. These three expressed that they believed students would come to them for help first (answering research question number three), because they made explicit that they preferred students go to them rather than other resources. Although they did express that they made other options available to their students. L said in an interview, "I want them to come to me first, because I'm going to know their work better than anyone else and that's what my office hours are for" (transcript 2B, p. 14 / audio 17:31). J reiterated the same point in saying, "I definitely want them to come to me first!" (transcript 1A, p. 5 / audio 16:23). M too expressed, "I do make sure to not only advertise my office hours, but also just plain lunch hours" (transcript 3A, p.3 / audio 6:28). These lunch hours were times that he made available to students beyond office hours.

$\mathrm{T}$, on the other hand, interacted more with his students via email, and encouraged his students to either go to writing tutorial services or to ask a native speaker for help. For T, encouraging his students to email him, go to writing tutorial services, or cultural centers may have resulted in him seeing less of his students in person, but it did result in more discussion from his students about the various other resources at the university. Students attended tutorial services instead of office hours, and inevitably talked about the efficacy of these resources to their instructor. Regardless of what form of additional help that these instructors urge their students to use, all these teachers did volunteer more of their own personal time to work with students individually both inside and out of class time, and they use various means to help these students cope with the different academic expectations that they are now facing.

Thus these teachers believe that students will essentially get help from the resources that are made overtly available to them. The instructors that encouraged students to ask them for help also stated in interviews that regardless of race or gender, particular students tend to be more adamant about receiving additional help, and they tend to be of a specific personality or demeanor. J explained that in regards to her own students "there are some that are just really proactive... usually it's the ones that are really worried about their grade" (transcript 1A, p. 3 / audio 9:57). T echoed the same notion in saying "I think the students who really are trying to get a certain grade" are the ones that will "usually come in" (transcript 4A, p. 2 / audio 6:17). Even M stated, "I find that the students who are the most interested, whether male or female, are usually the ones who are self-starters" (transcript 3A, p. 12 / audio 42:23). The only slight discrepancy about how these students approach their teachers was in the number of students who would do so. One teacher explained a unique trend of her students feeling more comfortable when going in groups to get such help. J explained, “They come in pairs, because they don't want to come alone... I think probably in China and Korea you don't go individually to ask the teacher questions because you feel like you're imposing on their time" 
(transcript 1A, p. 3 / audio 9:41). However for L and M, students typically came to office hours alone (personal communications).

As Intercultural Rhetoric suggests and in answer to research question number four, these instructors all recognized the challenges that they face with international students and the possible stereotypes that they, themselves, may have. $\mathrm{L}$ exemplifies this complexity in a reflection of her own teaching experience, with a student that wanted to discuss the flux of information that was now available to him, in stating: "My own ethnocentric bias prevented me from thinking about the information environment and the realities of censorship in China and that is an issue that he cares a lot about" (post-office hour conversation with researcher: Fieldnotes-04/23/2014). In acknowledging her own bias in an office hour meeting, and in turn through reflective teaching practices, she pushed against creating and perpetuating stereotypes. Such stereotypes are hard to combat and may even emanate from colleagues. For example, $\mathrm{L}$ reiterates that she "heard from people that these students don't want to talk one on one and that they do better in groups" (transcript 2B, p. 8 / audio 2:13). M also heard a similar stereotype, but fights against it in his remark, "I like the interaction because they are much more interactive than anybody would proclaim that they are" (transcript 3A, p. 3 / audio $6: 28)$. However, no matter how well intentioned teachers may be, stereotyping is a slippery slope that can easily begin with a simple comparison of assumptions about the two different cultures, which can turn into marginalization. One of the participants accidentally fell into this, and only upon reflection of the original transcript noticed the possible marginalization. This person gave permission to include the quote with added anonymity.

I know that most of these kids were sitting down at desks, just like these that we are sitting at and they were learning, for twelve hours a day. I gotta say some of these kids have PTSD. Some of these kids are basically abused children, they have not had childhoods, they have not had time to grow their brains, and this is one of the last chances we will have as educators to do something about that. And so, the more I can do about that the better I feel, and the more they all learn and end up being successful emotionally well rounded and interesting human beings as a opposed to drones (transcript X, p.8 / audio 28:30).

Although this instructor had good intentions, they unintentionally belittled the previous educational system of the international student population.

Additionally, answering question number four, these instructors found that this particular teaching situation was one of the most rewarding. M was enthusiastic in his ability to teach international students new concepts that they had yet to be exposed to, and he expressed this opportunity in stating, "Hey! Perfect, you will be our blank slate! Let's fill you up with some stuff" (transcript 3A, p. 11 / audio 38:00). The idea that international students lacked exposure to certain American academic constructs was a smaller theme that many of the instructors noticed. In the context of new and exciting ideas, this blank slate mentality can be seen as an opportunity. However, many teachers of international students take this blank slate mentality to the extreme where the held belief is that students do not bring any viable information with them from their home countries (Pinker, 2003). This deficit model 
of international students is a fallacy that all of these participants have been fighting against.

In fact, $\mathrm{L}$ in fighting against this model went as far as to include particular rhetorical strengths that she has witnessed solely in her international student population. She describes a tendency of her students to include a poetic phrase towards the end of an essay in which "every single word is lifting weight in the sentence" (transcript 2B, p. 6 / audio 11:40). She explains that this sentence is something that she highlights to her students as beautiful, and that is completely characteristic of their own personal rhetoric much like what Canagarajah argues for. She states:

When I encounter that sentence, I always have a joyous comment to the student because I want them to see just how excited I am about it. I will usually let them know that American students are not gonna do this, this is something that is to me an identifying move of a strong L2 writer... it's really an indication that they've kind of internalized certain western academic moves without having those moves replace the perspective that they bring (transcript 1A, p. 5 / audio 17:48).

Each of the four instructors who participated in this research echoed much of what previous scholars have discovered. For example, all of the teachers who had any experience in tutoring recognized that this training had positively affected their teaching abilities in the composition classroom, which is in support of the scholarship done by Shaughnessy (1973; 1977; 1998), Thonus $11993 ; 1999 ; 2001$; 2002; 2003; 2004), and others. These authors and the participants agree that any training they can obtain positively affects their abilities in the classroom. In regards to tutoring guiding the instruction of the course, M said, "I have interacted on a oneon-one basis and I kind of like that format" (transcript 3A, p. 5 / audio 14:25). J agreed by saying, "a big part of my teaching this class is tutoring" (transcript 1A, p. 5 / audio 17:48).

In addition to teachers asking for help in their training of how to engage with and better teach international students, teachers have also been calling for more supportive services for these students. J stated in regards to the resources currently available for NNS students "there aren't that many" (transcript 1A, p. 4 / audio 14:05). So instead, she encourages them to come to her. However, teachers cannot remain the sole ambassadors to a western academia, if the universities continue to recruit such a vast number of international students.

Finally, again in response to question number four, each of the participants acknowledged that although difficult at times, especially due to the amount of time students require of them, their position as an international student instructor of English composition was one of the most important and rewarding positions available. For L, who dealt primarily with American students in English composition before switching to the international section of the course, she found new and interesting combinations of uses of the language "I think it's this nice hybrid of English or western syntax and argument and eastern sensibility" (transcript 2B, p. 6 / audio 13:00). For J, who had only ever worked with international students, it has always been extremely rewarding to see the immense growth of her students over the course of a semester "they're a pretty high level, which is FUN!" (transcript 1A, p. 
6 / audio 21:36). Finally, M declares: "I am so blessed to have these students!" (transcript 3A, p. 8 / audio 26:50).

\section{Implications}

Through the perspective of the four participants, this research has inductively discovered several common threads in the assistance of international students. The first line of defense for such students is the teacher, specifically of freshman English composition. Both in class and in office hours these teachers helped students to not only navigate writing in their non-native language, but also to cope with western academic expectations. It is in the opinion of these teachers that students will go to office hours for additional help, when specifically encouraged to do so, and they will gravitate more towards office hours that are more convenient for them, which tends to be right after class in the same location. If, however the teacher encourages them to go to writing tutorial services, then they will more likely seek help there.

In addition to the instruction that these teachers provide, any resources that they used to supplement the students education was viewed as incredibly helpful and appreciated. Teachers noticed that students responded well to the added technology in the classroom, due to the need of visual accommodation and repetition in the course. These resources not only reminded students of the course schedule but also enabled students to see the content of the course that they possibly missed orally. Teachers also accommodated students by slowing down their speech and eliminating unnecessarily difficult jargon, in an attempt to make the information more accessible to their students.

It is obvious that the degree of empathy held by these instructors for their students led them to not only accommodate for, but to also stand up for, the disenfranchised population of students. Beyond what these teachers did for their students on the classroom front, they combatted several stereotypes that have been perpetuated about international students. They resist comments and misperceptions that emanate from other instructors of other fields. They combat different prejudices that occur within their own classrooms. They even struggle against their own bias and ethnocentric assumptions. Finally, they view these difficulties not only as challenging but also as rewarding, because their position of instructor for international students to them is one of the most important and gratifying positions available.

This study, did, however experience some limitations. For example, the overwhelming acceptance of western methodologies, or the assumption that one methodology does in fact fit all, is both counterintuitive and damaging towards the internationalization of methodology (Gobo, 2011). Having said that, there is a long road ahead before these forced methodologies can be adapted or replaced to suit each research contexts needs. Therefore, while I understand that this framework comes from a primarily western perspective of research, I do also acknowledge that recognition is the first step in broadening this study's horizons. Additionally, a discrepant case analysis was conducted in tandem with the survey, however proved 
to be unsuccessful. Perhaps the most damaging limitation was that of technological malfunctions. The audio recording device timed out during an interview, which lost valuable data. Finally, the administrative or student perceptions were not included, although these perspectives will be anticipated in future studies.

\section{Future directions}

This article is the first in a series of articles by the author, which attends to the difficulties international students face in American Universities; along with the various resources that they use in order to cope with these difficulties. After assessing the first form of academic support found in teachers of multilingual freshman composition, and understanding that they are the first line of defense for students, it is essential to take the next logical step of researching other resources used by international students. In order to discover what resources are known and used by international students, data must be collected from the students to lead to necessary resources that should be assessed. Scholars should not only consider the academic resources that institutions provide their international student population, but also the social support. This will ensure that the current resources are fulfilling the needs of the students, while also leading towards great advances in the formulation of future resources for these disenfranchised students.

Furthermore, scholars should look beyond what has simply been done in an American academic context, in order to discover new and useful tools that are more familiar to the cultures of these students. For example, Gairín, Feixas, Franch, Guillamón, and Quinquer (2002), made very astute claims in support of more resources for NNS, not only for academic support (like teachers, tutors, and the various forms of academic development that they may provide) but also for sociological support such as: linguistic competence, integration, adaptation to academia, relationships with peers, etc. Additionally, Ramsay, Jones, and Barker (2007) in Australia also acknowledge the need for both academic and social support. These studies are just the beginning.

In addition to this call for action, many questions are waiting to be answered by future research. For example, there is a lack of discussion on reading as a tool for the learning of international students particularly in tutorials, as J stated, which is only supported by only Williams and Thonus. Additionally, there is a large gap in the literature on the miscommunications and the interplay that happens between international students and the various resources that they use. If anyone resource is unreceptive to non-native speakers of English, what effect or impact will this have on the students? Will they be willing to try again, or go to a different resource? Are these various resources trained to help international students? Very little is known about the resources that these international students actually use, let alone what NNS student preference of resources may be. These are immense gaps in academic literature, which further research must attend to, and are the arenas where I hope to spark discussion and engage in future studies. 


\section{References}

Belenky, M. F., Clinchy, B. M., Goldberger, N. R., \& Tarule, J. (1986). Women's ways of knowing: The development of self, voice, and mind. New York: Basic Books.

Bourdieu, P., \& Thompson, J. B. (1991). Language and symbolic power / Pierre Bourdieu; edited and introduced by John B. Thompson; translated by Gino Raymond and Matthew Adamson. Cambridge, Mass.: Harvard University Press, 1991.

Canagarajah, S. (2013). Literacy as translingual practice: Between communities and classrooms. New York: Routledge.

Connor, U. (2011). Intercultural rhetoric in the writing classroom. Ann Arbor, MI: The University of Michigan Press.

Gairín, J., Feixas, M., Franch, J., Guillamón, C. \& Quinquer, D., Elementos para la elaboración de planes de tutoría en la universidad. Contextos Educativos, 6-7 (2003-2004), 21-42.

Gobo, G. (2011). Glocalizing methodology? The encounter between local methodologies. International Journal of Social Research Methodology, 14(6), 417-437.

Ladd, P., \& Ruby Jr., R. (1999). Learning style and adjustment issues of international students. Journal of Education for Business, 74(6), 363.

McAllister, G., \& Irvine, J. (2002). The role of empathy in teaching culturally diverse students: A qualitative study of teachers' beliefs (English). Journal of Teacher Education, 53(5), 433-443.

Nakamaru, S. (2010). Lexical issues in writing center tutorials with international and US-educated multilingual writers. Journal of Second Language Writing, 19(2), 95-113.

Nan, F. (2012). Bridging the gap: Essential issues to address in recurring writing center appointments with Chinese ELL students. Writing Center Journal, 32(1), 50-63.

Pinker, S. (2003). The blank slate: The modern denial of human nature. London, UK: Penguin Random House.

Ramsay, S., Jones, E., \& Barker, M. (2007). Relationship between adjustment and support types: Young and mature-aged local and international first year university students. Higher Education, 54(2), 247-265.

Severino, C. (2004). International students in a learning center: Self-perceptions of their EFL and ESL preparation for academic writing in the U.S. Learning Assistance Review (TLAR), 9(2), 5-16.

Shaughnessy, M. (1973). Open admissions and the disadvantaged teacher. College Composition and Communication, (5). 401. 
Shaughnessy, M. (1977). Some needed research on writing. College Composition and Communication, (4), 317.

Shaughnessy, M. (1998). The miserable truth. Journal of Basic Writing, 17, (2), 106112.

Thonus, T. (1993). Tutors as teachers: Assisting ESL/EFL students in the writing center. Writing Center Journal, 13(2), 13-26.

Thonus, T. (1999). Dominance in academic writing tutorials: Gender, language proficiency, and the offering of suggestions. Discourse and Society, 10, 225248.

Thonus, T. (2001). Journal writing in the language learning component of a teacher education course. In J. Burton \& M. Carroll (Eds.), Case Studies in TESOL Practice: Journal Writing in TESOL (pp. 101-112). Alexandria, VA: TESOL.

Thonus, T. (2002). Tutor and student assessments of academic writing tutorials: What is "success"? Assessing Writing, 8, 110-134.

Thonus, T. (2003). Serving generation 1.5 learners in the university writing center. TESOL Journal, 12, 17-24.

Thonus, T. (2004). What are the differences? Tutor interactions with first- and second-language writers. Journal of Second Language Writing, 13, 227-242.

Vygotsky, L. S. (1978). Mind and society: The development of higher mental processes. Cambridge: Cambridge University Press.

Williams, J. (2002). Undergraduate second language writers in the writing center. Journal of Basic Writing, 21(2), 73-91. 


\section{Appendix A}

\section{Interview questions for English W-131 Multilingual Instructors:}

1. How many students do you have?

2. What nationalities are they?

3. How old are they (what grade level)?

4. What kind of help (in your own opinion) do they most often need?

5. What kind of help do your students think they most often need?

6. How often do they ask for this kind of help? (For help with grammar?)

7. How much assistance do you provide students in this area?

8. Do you have experience in tutoring English? Do you find teaching different than tutoring?

9. When during the course of an essay do students tend to ask for your help the most?

10. Do you encourage your students to get help from other resources? If so, where?

11. How often do they go to your office hours? To Writing Tutorial Services (that you know of)? To the Asian Cultural Center (that you know of)?

12. What gender of student most frequently comes to your office hours? Can you give me a ratio?

13. Which students tend to be most adamant about getting your help?

14. Is there a difference between the way men ask for help versus the way women ask for help? What about nationality?

15. What teaching strategies have you adopted to help this population of students?

16. Tell me a time when you had to help an international student cope with writing in their nonnative language (English)... 